\title{
Some Aspects of the Histological Structure of Liver in Rainbow Trout (Oncorhynchus mykiss) under the Influence of Growth Systems
}

\author{
Vioara MIREŞAN ${ }^{1}$, Daniel COCAN*1), Viorel MICLĂUŞ ${ }^{2}$, Radu CONSTANTINESCU ${ }^{1)}$, Camelia RĂDUCU ${ }^{1)}$, \\ Octavian NEGREA ${ }^{1)}$ \\ ${ }^{1)}$ Faculty of Animal Science and Biotechnologies, University of Agricultural Sciences and Veterinary \\ Medicine, 3-5 Mănăştur Street, 400372 Cluj-Napoca, Romania \\ ${ }^{2)}$ Faculty of Veterinary Medicine, University of Agricultural Sciences and Veterinary Medicine 3-5 \\ Mănăştur Street, 400372 Cluj-Napoca, Romania \\ *Corresponding author, email: cocandaniel@yahoo.com
}

Bulletin UASVM Animal Science and Biotechnologies 71(2) / 2014,

Print ISSN 1843-5262; Electronic ISSN 1843-536X

DOI:10.15835/buasvmcn-asb:10786

\begin{abstract}
Because recirculating systems for breeding fish (in general) and trout (in particular), are more and more used in fish production and aquaculture, we investigated the influence of two different growth systems (classic system vs. recirculating system) on the fish health. Physiological status of trout was evaluated by histological investigations made at the liver level. At trout reared in the classical system, histological changes have not been major. At trout reared in a recirculating system, where environmental conditions are maintained at optimum parameters, voluntary feed intake (much enhanced by optimal environmental conditions), led to the appearance of massive lipid inclusion, such as the liver appears to be a hypertrophic fat mass. This may lead to the occurrence of the diseases and could endanger fish production.
\end{abstract}

Keywords: rainbow trout, liver, histological structure, growth systems

Introduction. Rainbow trout is the most exploited species of trout in the world and also in Romania. For achieving higher production, it is exploited in superintensive growth systems. These farming systems can cause in certain situations, different kind histological changes in some organs such as the liver (Haghighi et al., 2010; Monfared and Soltani, 2013; Banaee et al., 2013). This may lead to the occurrence of the diseases and could endanger fish production. Histological study of an organism is important because all biochemical, biophysical and physiological processes, underpinning development from the sperm or egg stage, until the body taken as a whole, is based on histological structures at the cellular and tissue.

Aims and objectives. In this study, we wanted to highlight the histological changes of rainbow trout liver, under the influence of growth systems, knowing that in recirculating systems, fish appetite is much amplified. In the literature of our country, there are very few data on the histological structures of the systems and apparatus of fish (in general) and trout in particular. Therefore, we want to contribute with this paper to complement the existing data in the specialty literature.

Materials and methods. 5 samples of liver were taken from 10 rainbow trout, reared in different farming systems (5 rainbow trout from a classical growth system and 5 rainbow trout from a recirculating system). After fixation in formalin $15 \%$, the pieces were processed by inclusion in paraffin, through all stages of hydration, rehydration and microtome sectioning at $7 \mu \mathrm{m}$. We used trichromic staining protocols. For microscopic imaging we used objective with magnification power of $10 \mathrm{X}, 20 \mathrm{X}$ and $40 \mathrm{X}$. The 


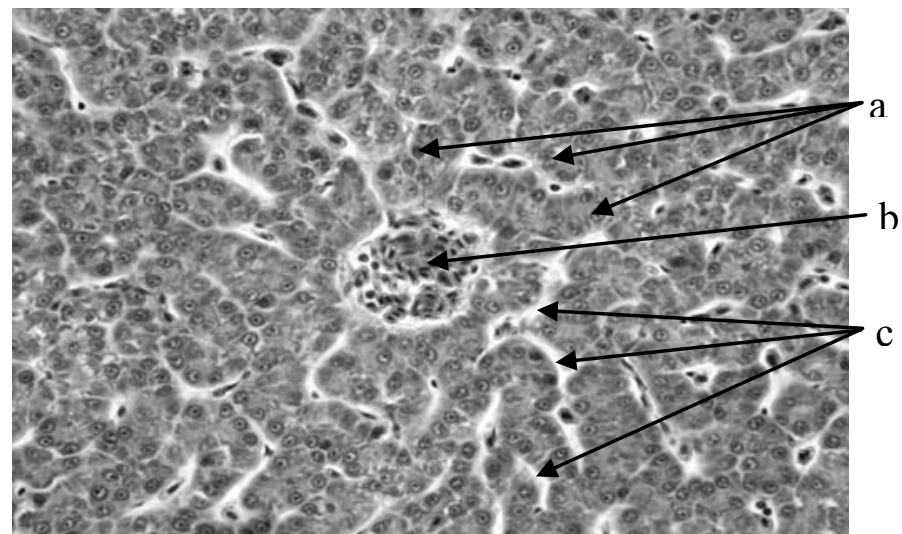

Fig. 1. Liver control group: a-hepatocytes rows; b-central-lobular venula; c-sinusoids capillary; (Trichrom Goldner-ob. 40X) (Original)

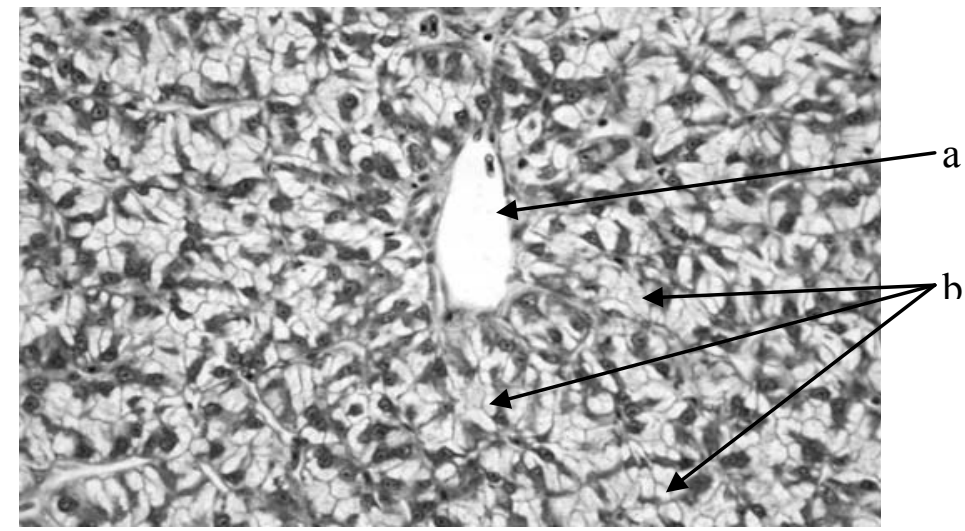

Fig. 2. Experimental group liver: a-central-lobular venula; b-hepatocytes with large lipid inclusions

images used in this paper are accompanied by such specifications.

Results and discussion. At the control group (from classical growth system), liver are with a normal structure that consist of liver lobules, formed from hepatocytes cordons. These cordons converge to centrilobular venula and among sinusoids capillary. Hepatocyte aspect is normal and does not indicate the presence of lipid inclusions into cytoplasm (Fig. 1). In the experimental group (from recirculating system) the situation is different in the sense that hepatocytes are so loaded with fat that appear hypertrophied. As a whole, the liver appears as a generalized mass of fat (Fig. 2).

Conclusion. After the appearance of the liver in fish from the two groups, we can say that for the control group there is a certain balance between intake and consumption so that the body does not have in excess substances that store them in the form of triglycerides in hepatocytes. At the fish from the experimental group, intake exceeds more consumption and therefore the surplus is stored in hepatocytes at an impressive level.

\section{REFERENCES}

1. Haghighi S, Akhlaghi M, Mansouri H (2010). Histological study of spleen, liver and intestine of rainbow trout (Oncorhynchus mykiss). Journal of Aquatic Sciences, 1(3): 71-83.

2. Monfared AL, Soltani S (2013). Effects of silver nanoparticles administration on the liver of rainbow trout (Oncorhynchus mykiss): histological and biochemical studies. European Journal of Experimental Biology, 3(2): 285-289.

3. Banaee M, Sureda A, Mirvaghefi AR, Ahmadi K (2013). Biochemical and histological changes in the liver tissue of rainbow trout (Oncorhynchus mykiss) exposed to sub-lethal concentrations of diazinon. Fish Physiol. Biochem, 39(3): 489-501. 